\title{
The Phase Shifting Soft Startup of L-LLC Resonant Bidirectional DC-DC Converter Based on Current-Limiting Curve
}

\author{
Jing Lu $(\mathbb{D}$, Xiangqian Tong $(\mathbb{D}$, Ming Shen $(\mathbb{D}$, Jun Yin $(\mathbb{D}$, and Yongtao Yuan \\ School of Electrical Engineering, Xi'an University of Technology, Xi'an 710048, China \\ Correspondence should be addressed to Xiangqian Tong; lstong@mail.xaut.edu.cn
}

Received 11 November 2020; Accepted 10 March 2021; Published 20 March 2021

Academic Editor: Andras Szekrenyes

Copyright ( 2021 Jing Lu et al. This is an open access article distributed under the Creative Commons Attribution License, which permits unrestricted use, distribution, and reproduction in any medium, provided the original work is properly cited.

\begin{abstract}
The new L-LLC resonant bidirectional DC-DC converter (L-LLC-BDC) will produce a large resonance current and voltage inrush during the startup, posing a threat to the safe operation of the power device. Although a very high starting frequency can effectively suppress the inrush, it will also increase the output current demand of the driving ICs. This paper proposes a phase-shifting soft-start control strategy based on the current-limiting curve. Using operating mode analysis, the peak value of the resonant current is limited according to the output voltage and the phase shift angle of the switch, with the limit current curve at the startup stage drawn. By this current curve, a one-to-one correspondence between the output voltage and the phase shift angle of the switch is obtained. The phase-shifted soft-start control strategy can quickly establish the output voltage on the basis of a resonant frequency and can effectively suppress the resonance current inrush. An experimental prototype with a power of $6 \mathrm{~kW}$ and an input of $760 \mathrm{~V}$ and an output of $380 \mathrm{~V}$ is built. The experimental results prove the correctness and effectiveness of the soft start control strategy proposed in this paper.
\end{abstract}

\section{Introduction}

Due to LLC resonant converter's high efficiency, high power density, and wide gain and power, there are many researchers focusing on it [1-3]. Twelve switches are used in the LLC converter in literature [4], the cost of the converter is increased, and it also reduces the power density because of the two transformers. Literature [5] proposed an LLC converter with two interleaved pulse-width rectifiers, and it only operated with forward power transmission. The CLLC resonant converter is proposed in [6] for bidirectional power flow. However, the voltage gain of the converter is not monotonous in inductive region under heavy load. In literature [7], an additional inductance is added to the traditional LLC resonant converter to form an L-LLC resonant bidirectional DC-DC converter. Eight switches are used in this converter, and the converter can be operated at both boost and buck voltage gain with forward and reverse transmission. The efficiency of the topology used in this paper is up to $97 \%$ by using synchronous variable width variable frequency control. This paper employs the topology from literature [7] as shown in Figure 1. It can be used as the key equipment for interaction between ESSs and the DC microgrid for stabilization of the DC bus voltage. Figure 2 shows the DC characteristics of the converter with different loads. In order to obtain the highest working efficiency, the converter generally works around the switching frequency $f$ equal to the resonance frequency $f_{r}$, i.e., the normalized frequency $f_{n}=f / f_{r}=1$. The voltage gain $M$ is the ratio of the output voltage to the input voltage of the converter, and $M$ is 1 . When the input voltage decreases, the converter will work in the $f_{n}<1$, with $M$ being greater than 1 to keep the output voltage constant. Conversely, when the input voltage increases, the converter works in the $f_{n}>1$, so as to prevent the converter from entering the zero current (ZCS) region during startup process, and the switching frequency at the initial stage of startup must be greater than the resonance frequency $[8,9]$. When the switching frequency in the startup is not large enough, that is, when the maximum switching startup frequency $f_{\max }=1.5 f_{r}$, a large voltage and current inrush will occur as shown in Figure 3. When the switching frequency in the startup phase is large enough, 


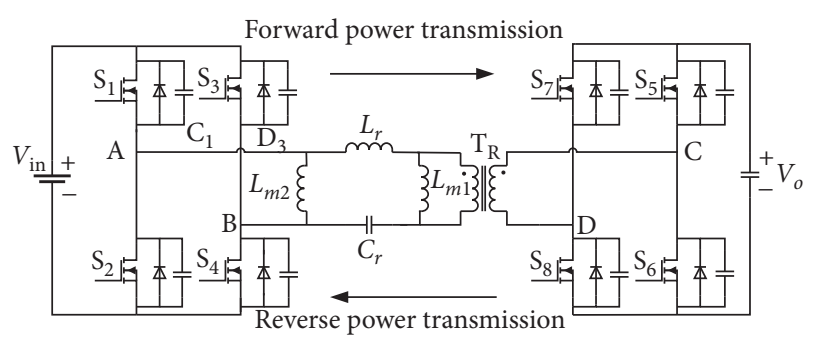

Figure 1: L-LLC-BDC circuit topology.
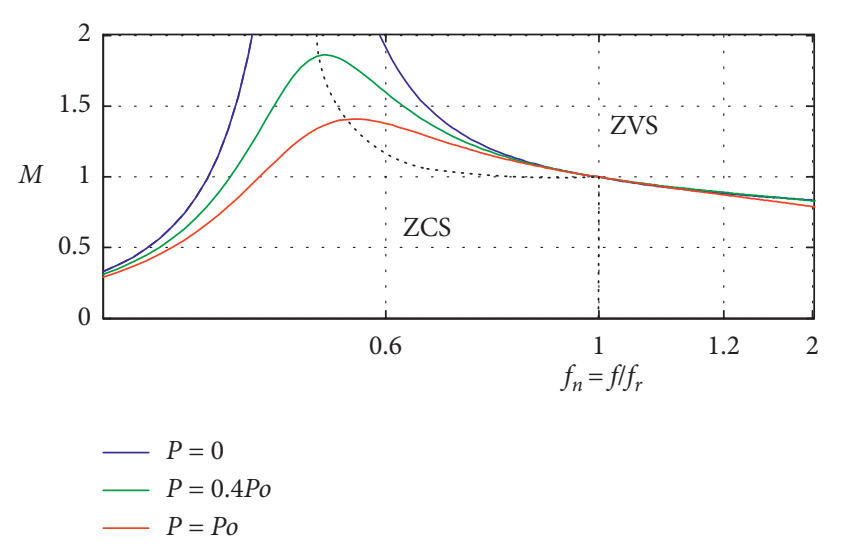

Figure 2: DC characteristics of L-LLC-BDC.

$f_{\max }=5 f_{r}$. Although there is no large voltage and current stress at the initial stage of the start-up process, too large voltage and current surge will still occur if the switching frequency is reduced too quickly, and if the switching frequency decreases too slowly, the output voltage will be set up too slowly.

The pulse frequency modulation (PFM) control strategy is adopted, and the relationship between $f_{n}$ and maximum primary current $i_{\text {pmax }}$ with different filter parameters is plotted in the soft startup as shown in Figure 4. The maximum resonant current will not decrease as the switching frequency increases when $f_{n}>3$. The minimum switching start frequency can be determined if the maximum resonant current is set. Therefore, the switching frequency is relatively large as long as the PFM control strategy is used during soft startup.

At a lower switching frequency, no large voltage and current stress occur during the rapid establishment of the output voltage, which is a key issue for the soft startup of the converter. The phase shift control is widely used in resonant converters [10-14]. In literature [14], a variable duty cycle soft start control strategy is proposed, but the mode prediction calculation by this method is too complicated. In literature [15], a two-step method is proposed. In the soft startup, the two switches $S_{3}$ and $S_{4}$ are forcibly turned off to make the converter work on the half-bridge, and the fullbridge working state is restored once the output voltage reaches the steady-state. However, the experimental results show that inrush current still occurs during the startup process, and that the startup frequency is also very high. Reference [16] only proposed a three-step control strategy

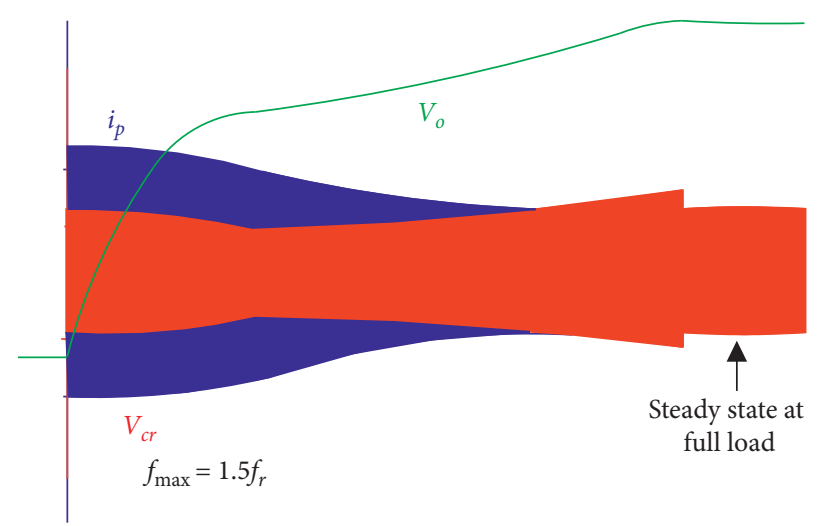

FIgURE 3: Soft startup at a low switching frequency.

for a boost PFC rectifier, which has limited application. In literature [17], the optimal trajectory soft startup control strategy based on microcontroller, such as DSP is proposed. This method eliminates the voltage and current surges during the startup process, with its essence being PFM control and the startup frequency being still relatively high. In literature [18-24], the control process is too complex, and the time of setting up the output voltage is too slow. Reference [25] uses analog circuit to realize soft start, and although the starting speed of output voltage is fast and the current inrush is small, it is not desirable for resonant converter with high power density. Reference [26] proposes a three-step soft-shift start modulation technique that allows to limit the inrush current in the DC/DC isolation stage during the DC-link capacitors precharging for a three-stage smart transformer, but it is for nonresonant circuits only.

This paper proposes a phase-shifting soft-start control strategy based on the current-limiting curve. Using the operating mode analysis [27-30], the peak value of the primary current $i_{p}$ of the converter is limited according to the output voltage and the phase-shifting angle of the switch, and it is not necessary to predict the operating mode of the converter to obtain the current peak, thereby obtaining the limiting current curve in the startup. Based on this current curve, a one-to-one correspondence between output voltage and phase-shifting angle is obtained. The output voltage can be quickly established on the basis of a lower starting frequency, and the resonance current surge can be effectively suppressed.

\section{Working Principle of Bidirectional L-LLC- BDC}

Figure 1 shows the circuit topology of L-LLC-BDC. The primary side and secondary side of the converter adopt a full-bridge structure, and $V_{i n}$ of the converter is the input voltage of the interface unit of the energy storage device. $n V_{o}$ is the DC bus voltage, $L_{m 1}$ is the magnetizing inductance, $L_{r}$ is the resonant inductance, $C_{r}$ is the resonant capacitance, and $L_{m 2}$ is the additional inductance. The switches $S_{1}-S_{4}$ are primary side switches and $S_{5}-S_{8}$ are secondary side switches. $V_{L m 1}$ is the voltage of the magnetizing inductance $L_{m 1}$ when the converter works in the forward direction. When the 


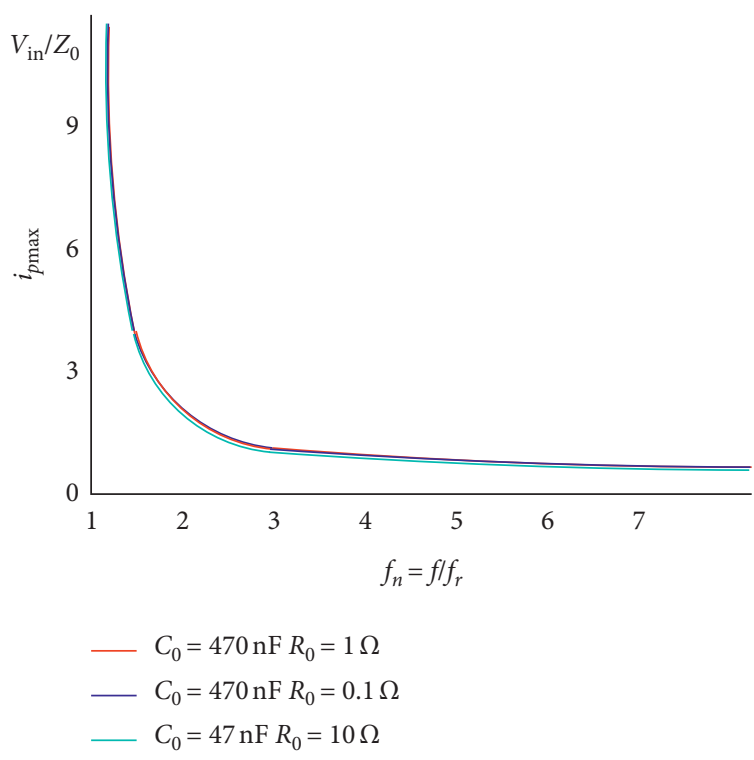

FIGURE 4: Relationship between startup current and frequency with different output filter parameters.

magnetizing inductance is clamped at the output voltage $n V_{0}, U_{L m 1}=n V_{O}$. When the magnetizing inductance is clamped reversely at the output voltage $n V_{0}, U_{L m 1}=-n V_{O}$. When the converter is in the freewheeling stage, that is, the LLC resonance, $U_{L m 1}<n V_{O}$. The voltage of the additional inductance $L_{m 2}$ is the same as $L_{m 1}$ with the reverse power transmission. The forward operation of the converter is the discharge mode, and the reverse operation is the charge mode. If the additional inductance of $L_{m 2}$ is equal to the magnetizing inductance of $L_{m 1}$, the forward and reverse working principles of the converter are exactly the same, so this article only analyzes the forward working principle of the converter. The switches $S_{1}-S_{4}$ form an inverter network, $L_{m 2}, L_{m 1}, L_{r}$, and $C_{r}$ form a resonant network, and the antiparallel diodes $D s_{5}-D s_{8}$ of the switches $S_{5}-S_{8}$ form a rectifier network. When the converter is working in the forward direction, $S_{1}$ and $S_{4}$ form the leading bridge arm, $S_{2}$ and $S_{3}$ form the lagging bridge arm, and any switching is a complementary drive signal with the same frequency and a $50 \%$ duty cycle. The output voltage $V_{o}$ is modulated by adjusting the phase shift angle between the leading arm and the lagging arm. $\theta$ is the phase-shifting angle, $\theta \in[0, \pi]$, and $f_{r}$ is the resonant frequency. The additional inductance $L_{m 2}$ never participates in resonance when the converter is working in the forward direction, but helps the primary side switch to achieve ZVS. In the reverse operation of the converter, the additional inductance $L_{m 2}$ forms part of the resonant network, and the magnetizing inductance $L_{m 1}$ never participates in resonance, helping the secondary side switch to achieve ZVS.

L-LLC-BDC has multiple operating modes under different phase-shift angles with the phase-shift control strategy. The working principle of the first half cycle and the second half cycle is the same, so only the working state of the first half cycle is analyzed, without considering the dead time. The operating modes of this converter are as follows.

2.1. Mode P. $v_{A B}=V_{i n}$. Switches $S_{1}$ and $S_{4}$ are turned on, the primary current $i_{p}$ continues to flow through $D_{S 1}$ and $D_{S 4}$, the output capacitors $C_{S 1}$ and $C_{S 4}$ of the switch are discharged to zero voltage, and switches $S_{1}$ and $S_{4}$ realize ZVS. The voltage across the two points $\mathrm{A}$ and $\mathrm{B}$ which is $V_{i n}, i_{p}$, $i_{L m 1}$, and $i_{L m 2}$ begins to increase. The body diodes $D_{S 5}$ and $D_{S 8}$ of the secondary side switches $S_{5}$ and $S_{8}$ are turned on with $i_{P}$ increasing faster. The $\mathrm{C}-\mathrm{D}$ two-point voltage is clamped at the output voltage $V_{o}, i_{P}$ flows through switches $S_{1}$ and $S_{4}$ to transfer energy to the load. It is worth noting that, in this mode, the primary current $i_{p}=i_{L r}+i_{L m 2}$, and the secondary current $i_{s}=n i_{L r}-n i_{L m 1}$.

2.2. Mode O. $v_{A B}=V_{i n}$. The resonant current $i_{L r}$ is equal to the magnetizing current $i_{L m 1}$, and the secondary side current is zero. The body diodes $D_{S 5}$ and $D_{S 8}$ of switches $S_{5}$ and $S_{8}$ are naturally turned off because the current is zero, with no reverse recovery loss, and the ZCS of the secondary side switch tube is realized. The output voltage is no longer clamped to the C-D two points, and the output capacitors $C_{S 5}$ to $C_{S 8}$ of switches $S_{5}$ and $S_{8}$ participate in resonance. This stage is actually a freewheeling stage.

2.3. Mode $P_{0} \cdot v_{A B}=0$, and the operating mode is similar to the $\mathrm{P}$ mode.

2.4. Mode $O_{0} \cdot v_{A B}=0$, and the operating mode is similar to the $\mathrm{O}$ mode. 
2.5. Mode $N_{0} . v_{A B}=0$. Switches $S_{1}$ and $S_{4}$ are turned on, the primary side current $i_{p}$ continues to flow through $D_{S 1}$ and $D_{S 2}, C_{S 1}$ and $C_{S 4}$ discharge to zero voltage, and the switches $S_{1}$ and $S_{4}$ realize the ZVS. The body diodes $D_{S 6}$ and $D_{S 7}$ of the secondary side switches $S_{6}$ and $S_{7}$ are turned on, and the voltage across $C$ and $\mathrm{D}$ is clamped to the output voltage $-V_{o}$. The equivalent circuit of the five modes of the converter is shown in Figure 5.

\section{Time-Domain Equation of Bidirectional L-LLC-BDC}

The time-domain equations of the above five mode equivalent circuits can be expressed as follows.

3.1. Mode P. By normalizing all voltages with voltage factor $n V_{0}$, the normalized all currents with the current factor $I=n V_{0} / Z_{r}$.

$$
\left\{\begin{array}{l}
i_{L r P}(\omega t)=I_{L r P} \sin \left[\omega\left(t+t_{P 0}\right)\right], \\
i_{P P}(\omega t)=I_{P P}+\frac{\omega t}{k}, \\
u_{C r P}(\omega t)=-I_{L r P} \cos \left[\omega\left(t+t_{P 0}\right)\right]+\frac{1}{M}-1, \\
i_{L m 1 P}(\omega t)=I_{L m 1 P}+\frac{\omega t}{k M},
\end{array}\right.
$$

where $Z_{r}$ is the characteristic impedance, $Z_{r}=\sqrt{L_{r} / C_{r}}$, $k=L_{m 1} / L_{r}, \omega$ is the resonance angular frequency $\omega=2 \pi f, M$ is the voltage gain $M=n V_{o} / V_{\text {in }}, 0 \leq \omega t \leq \omega t_{P}$, and $I_{L r P} I_{L m 1 P}$, $I_{P P}, \omega t, \omega t_{P 0}$, and $M$ are unknown quantities.

\subsection{Mode $O$}

$$
\left\{\begin{array}{l}
i_{\text {LrO }}(\omega t)=i_{P O}=I_{\text {Lro }} \sin \left[\omega\left(\sqrt{\frac{1}{1+k}} t+t_{O 0}\right)\right], \\
i_{L m 1 P}(\omega t)=I_{L m 1 O}+\frac{\omega t}{k M}, \\
u_{C r O}(\omega t)=-I_{L r O} \cos \left[\omega\left(\sqrt{\frac{1}{1+k}} t+t_{O 0}\right)\right]+\frac{1}{M}, \\
u_{L m 1 O}(\omega t)=\frac{(1 / M)+u_{C r O}(\omega t)}{1+k}
\end{array}\right.
$$

where $0 \leq \omega t \leq \omega t_{O}, I_{L r O}, I_{L m 1 O}, \omega t, \omega t_{O 0}$, and $M$ are unknown quantities.

\subsection{Mode $P_{0}$}

$$
\left\{\begin{array}{l}
i_{L r P_{0}}(\omega t)=I_{L r P_{0}} \sin \left[\omega\left(t+t_{P_{0} 0}\right)\right], \\
i_{P P_{0}}(\omega t)=I_{L m 1 P_{0}}+\frac{\omega t}{k}, \\
u_{C r P_{0}}(\omega t)=-I_{L r P_{0}} \cos \left[\omega\left(t+t_{P_{0} 0}\right)\right]-1, \\
i_{L m 1 P_{0}}(\omega t)=I_{P P_{0}},
\end{array}\right.
$$

where $0 \leq \omega t \leq \omega t_{P_{0}}, I_{L r P_{0}}, I_{L m 1 P_{0}}, \omega t, \omega t_{P_{0} 0}$, and $M$ are unknown quantities.

\subsection{Mode $N_{0}$}

$$
\left\{\begin{array}{l}
i_{L r N_{0}}(\omega t)=I_{L r N_{0}} \sin \left[\omega\left(t+t_{N_{0} 0}\right)\right], \\
i_{P N_{0}}(\omega t)=I_{L m 1 N_{0}}-\frac{\omega t}{k}, \\
u_{C r N_{0}}(\omega t)=-I_{L r N_{0}} \cos \left[\omega\left(t+t_{N_{0} 0}\right)\right]+1, \\
i_{P N_{0}}(\omega t)=I_{P N_{0}},
\end{array}\right.
$$

where $0 \leq \omega t \leq \omega t_{N_{0}}, I_{L r N_{0}}, I_{L m 1 N_{0}}, \omega t, \omega t_{N_{0} 0}$, and $M$ are unknown quantities.

\subsection{Mode $\mathrm{O}_{0}$}

$$
\begin{aligned}
& \int i_{L^{\prime} O_{0}}(\omega t)=i_{P O_{0}}=I_{L r O_{0}} \sin \left[\omega\left(\sqrt{\frac{1}{1+k}} t+t_{O_{0} 0}\right)\right], \\
& u_{L^{\prime} 1 O_{0}}(\omega t)=\frac{-u_{C r}(\omega t)}{1+k}, \\
& \begin{array}{l}
u_{\mathrm{CrO}_{0}}(\omega t)=-I_{\mathrm{LrO}_{0}} \cos \left[\omega\left(\sqrt{\frac{1}{1+k}} t+t_{\mathrm{O}_{0} 0}\right)\right], \\
i_{{\mathrm{Lm} 1 \mathrm{O}_{0}}}(\omega t)=I_{\mathrm{Lm}_{1 \mathrm{O}_{0}},}
\end{array}
\end{aligned}
$$

where $0 \leq \omega t \leq \omega t_{O_{0}}, I_{L r O_{0}}, I_{L m 1 O_{0}}, \omega t, \omega t_{O_{0} 0}$, and $M$ are unknown quantities.

L-LLC-BDC has 6 operating states formed by connecting these five modes in different orders with the increase of phase-shift angle $\theta$, with the operating states being $\mathrm{PP}_{0} \mathrm{O}_{0} \mathrm{~N}_{0}$, $\mathrm{PP}_{0} \mathrm{O}_{0}, \mathrm{OPP}_{0} \mathrm{O}_{0}, \mathrm{OPOO}_{0}, \mathrm{P}$, and $\mathrm{OPO}$. The time-domain waveform is shown in Figure 6. 


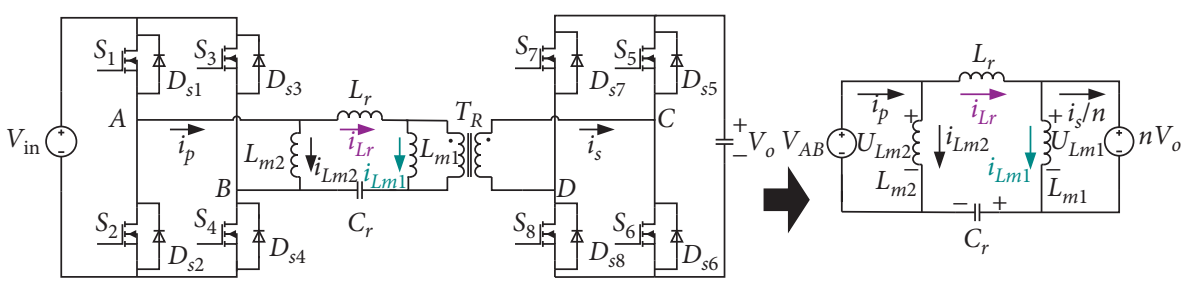

(a)

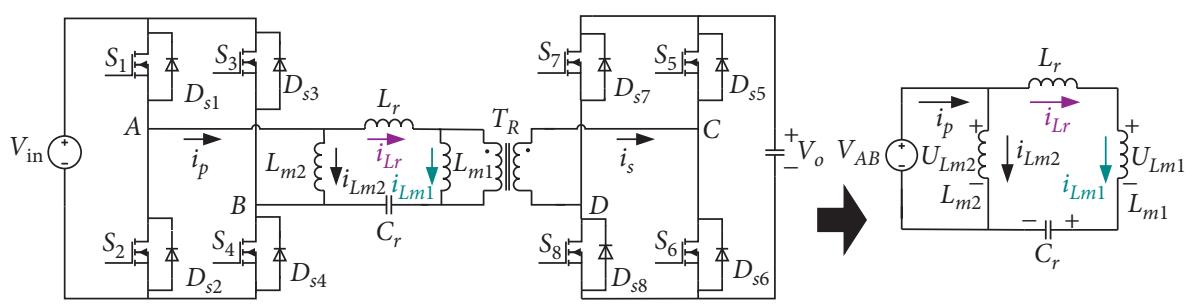

(b)

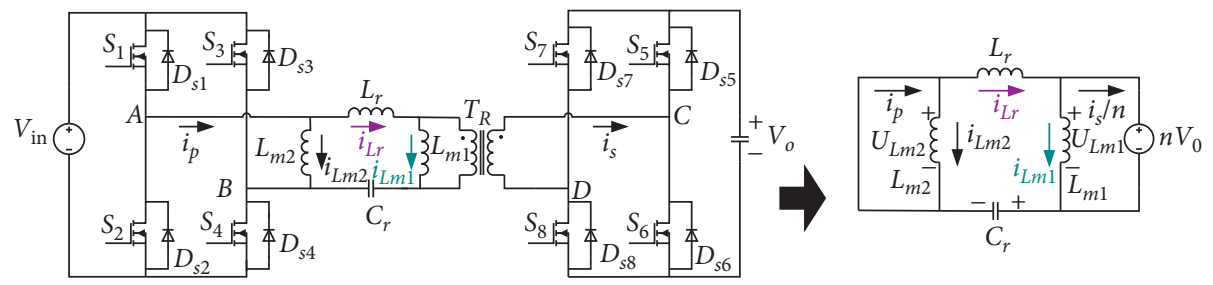

(c)

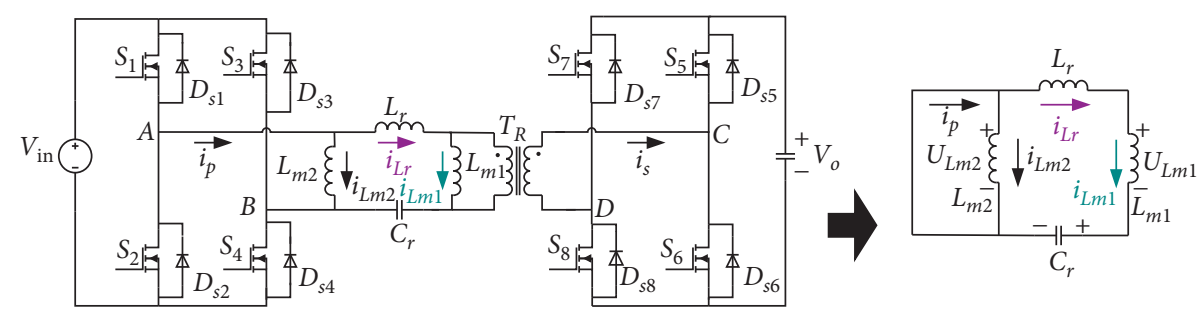

(d)

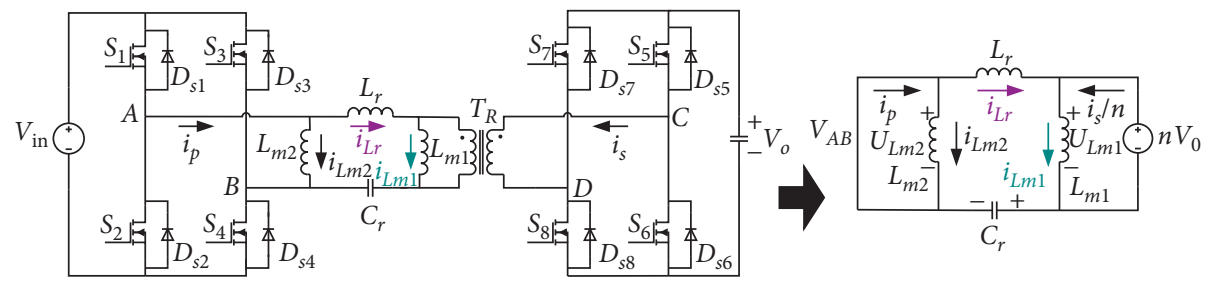

(e)

Figure 5: Simplified equivalent circuits with L-LLC-BDC under different modes. (a) Mode P. (b) Mode O. (c) Mode $\mathrm{P}_{0}$. (d) Mode $\mathrm{O}_{0}$. (e) Mode $\mathrm{N}_{0}$.

3.5.1. State $\mathrm{PP}_{0} \mathrm{O}_{0} \mathrm{~N}_{0}$. The converter enters the $\mathrm{PP}_{0} \mathrm{O}_{0} \mathrm{~N}_{0}$ state when the phase-shift angle $\theta$ is small. As shown in Figure 6(a), starting with mode $\mathrm{P}$, the converter enters $\mathrm{P}_{0}$ when the voltage of input is zero. The secondary diodes are turned off and enter to the $\mathrm{O}_{0}$ mode when the resonance current $i_{L r}$ is equal to the magnetizing current $i_{L m 1}$. When mode $\mathrm{O}_{0}$ ends, $L_{m 1}$ falls down to $-V_{O}$, diodes $D_{S 7}$ and $D_{S 6}$ of the secondary side are turned on, and $L_{m 1}$ is clamped at $-V_{O}$. The positive half cycle ends when the resonant inductance and magnetizing inductance are equal again.
3.5.2. State $P_{0} \mathrm{O}_{0}$. Increasing the load on the basis of the $\mathrm{PP}_{0} \mathrm{O}_{0} \mathrm{~N}_{0}$ state, or further increasing the phase-shift angle, the converter starts the $\mathrm{PP}_{0} \mathrm{O}_{0}$ state in Figure 6(b). The $\mathrm{PP}_{0} \mathrm{O}_{0}$ state is the same as the first three modes of the $\mathrm{PP}_{0} \mathrm{O}_{0} \mathrm{~N}_{0}$ state.

3.5.3. State $O P P_{0} O_{0}$. In Figure 6(c), with the increase of phase-shift angle $\theta$, the converter enters the $\mathrm{OPP}_{0} \mathrm{O}_{0}$ state, but this state only exists under light load conditions. The magnetizing inductance voltage $V_{L m 1}$ does not have enough 


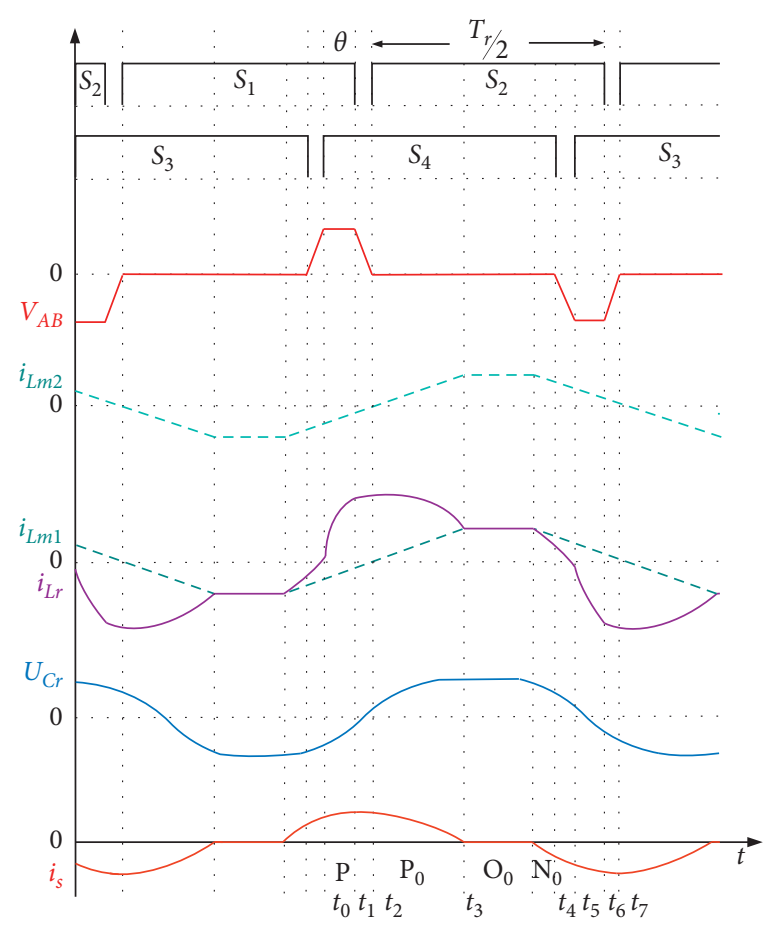

(a)

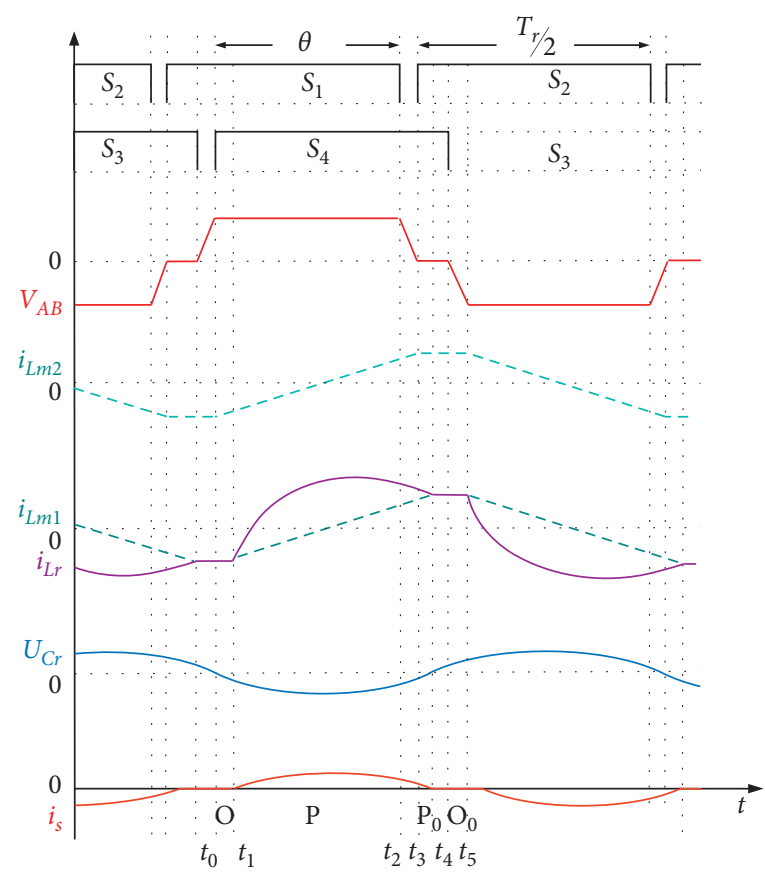

(c)

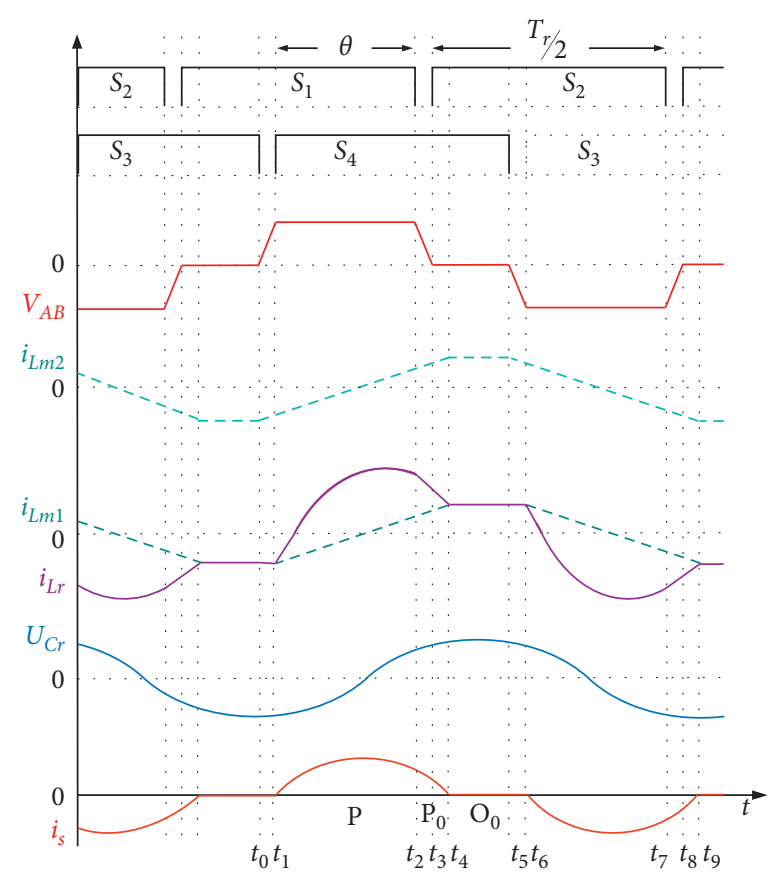

(b)

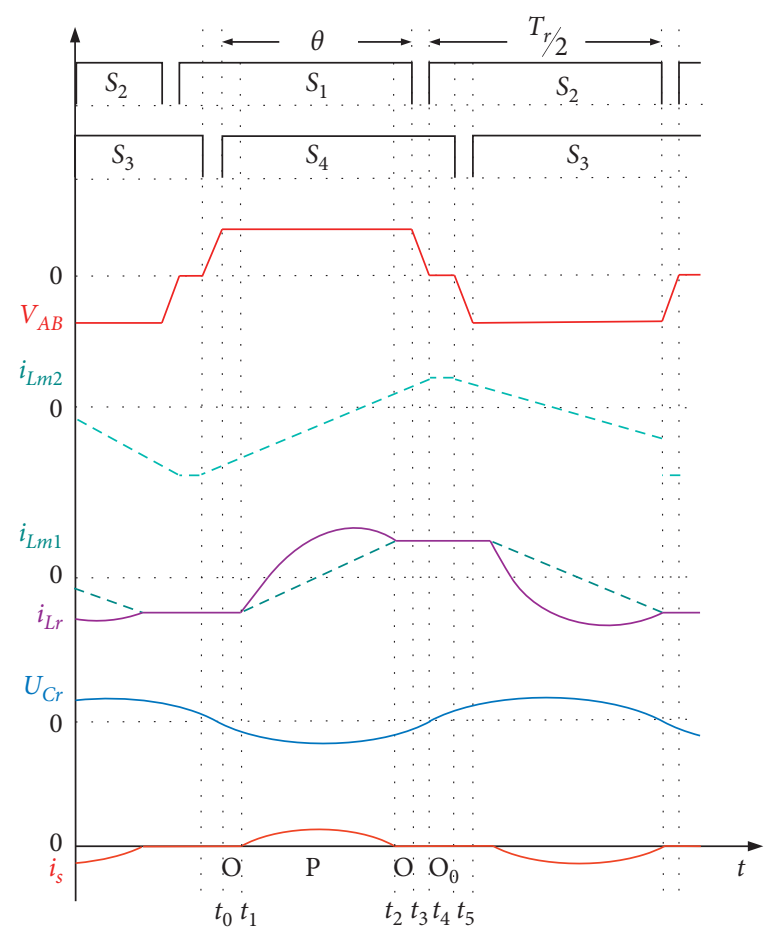

(d)

Figure 6: Continued. 


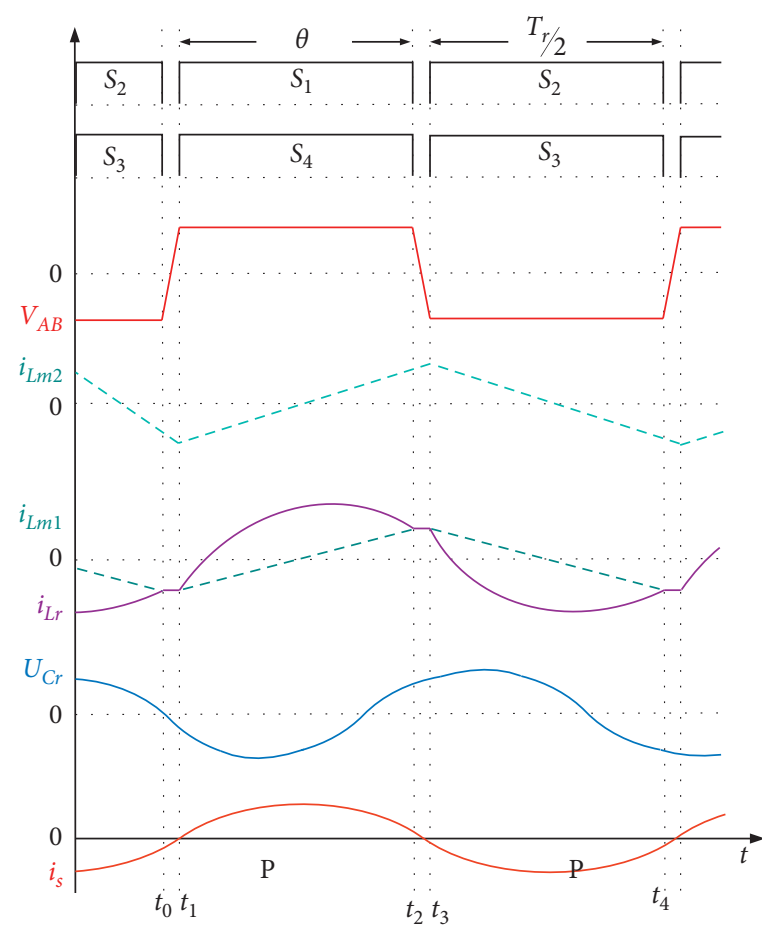

(e)

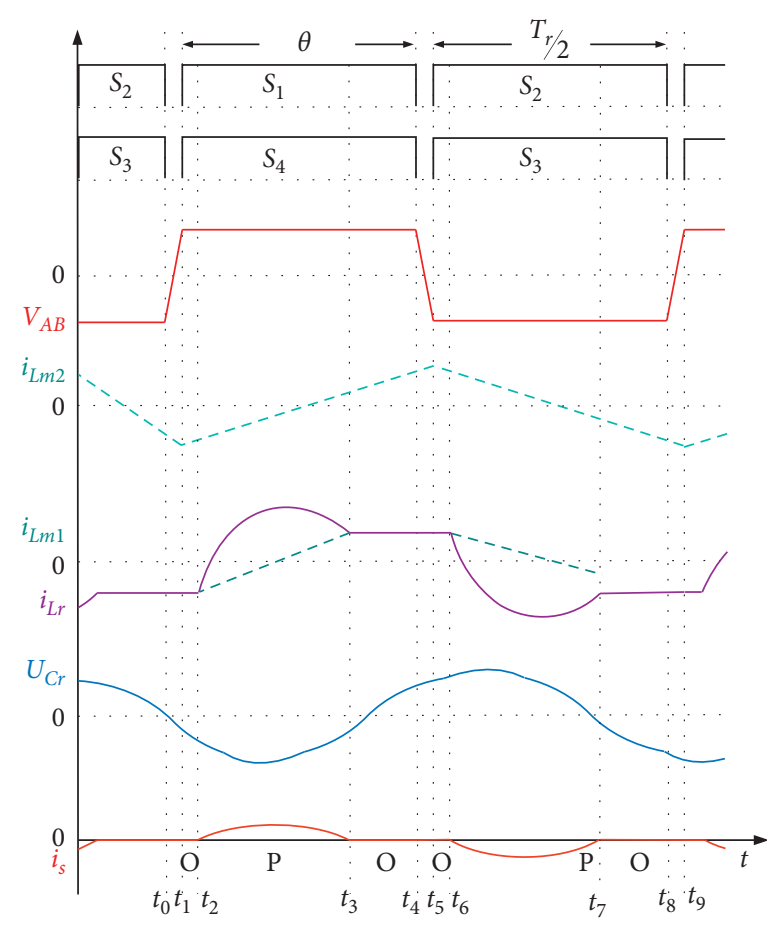

(f)

Figure 6: Time-domain waveforms for L-LLC-BDC in different states. (a) $\mathrm{PP}_{0} \mathrm{O}_{0} \mathrm{~N}_{0}$. (b) $\mathrm{PP}_{0} \mathrm{O}_{0}$. (c) $\mathrm{OPP}_{0} \mathrm{O}_{0}$. (d) OPOO $\mathrm{OP}_{0}$ (e) P. (f) OPO.

capacity to start the $\mathrm{P}$ mode, and therefore, the converter starts with the $\mathrm{O}$ mode and then enters the $\mathrm{P}$ mode. After the end of the $\mathrm{P}$ mode, the converter enters the $\mathrm{P}_{0}$ mode when the voltage of input is zero and ends in the $\mathrm{O}_{0}$ mode.

3.5.4. State $\mathrm{OPOO}_{0}$. With the increase of phase-shift angle $\theta$, the converter enters the $\mathrm{OPOO}_{0}$ state as shown in Figure 6(d), and this state only exists under light load conditions too, which is similar to the first two modes of the $\mathrm{OPP}_{0} \mathrm{O}_{0}$ state in Figure 6(c). After the end of the P mode, the converter enters the $\mathrm{O}$ mode and ends in the $\mathrm{O}_{0}$ mode when the voltage of input is zero.

3.5.5. States $P$ and $O P O$. When the phase-shift angles $\theta$ increases to the maximum value $\pi$, the converter has two operating states, respectively, as shown in Figures 6(e) and 6(f). The P state works at the resonant frequency point, which is the most ideal working state after the converter enters the steady state. The OPO operating state exists under the light load condition when the phase shift angle is $\pi$. At this time, the magnetizing inductance voltage $V_{L m 1}$ does not have enough capacity to start the $\mathrm{P}$ mode, and therefore, the converter works in mode $\mathrm{O}$. After mode $\mathrm{P}$, the magnetizing inductance voltage $V_{L m 1}$ is not low enough to enter mode N, which ends in mode $\mathrm{O}$.

The converter operates at the above six working states, and its time domain equations must satisfy the following stepwise continuous conditions and half-period symmetry conditions. $\mathrm{AB}$ is the two modes connected in a sequence in a certain operating state. Hh is a certain operating state at the beginning and end of the first half of the cycle, as shown in equations (6) and (7).

$$
\begin{aligned}
& \left\{\begin{array}{l}
i_{L r A}\left[\omega\left(t+t_{A}\right)\right]=i_{L r B}(0), \\
i_{L m 1 A}\left[\omega\left(t+t_{A}\right)\right]=i_{L m 1 B}(0), \\
u_{C r A}\left[\omega\left(t+t_{A}\right)\right]=u_{C r B}(0), \\
i_{p A}\left[\omega\left(t+t_{A}\right)\right]=i_{P B}(0),
\end{array}\right. \\
& \left\{\begin{array}{l}
-i_{L r H}\left[\omega\left(t+t_{H}\right)\right]=i_{L r h}(0), \\
-i_{L m 1 H}\left[\omega\left(t+t_{H}\right)\right]=i_{L m 1 h}(0), \\
-u_{C r H}\left[\omega\left(t+t_{H}\right)\right]=u_{C r h}(0), \\
-i_{p H}\left[\omega\left(t+t_{H}\right)\right]=i_{P h}(0) .
\end{array}\right.
\end{aligned}
$$

According to the mode analysis, the converter only transfers energy to the load in the $\mathrm{P}, \mathrm{P}_{0}$, and $\mathrm{N}_{0}$ stages. In mode $\mathrm{O}$ and mode $\mathrm{O}_{0}$, the secondary side discontinues, and there is no energy transfer. Therefore, the power balance conditions are

$$
\begin{aligned}
\frac{Z_{r} P_{O}}{n^{2} V_{O}^{2}}= & \frac{1}{\pi}\left[\int_{0}^{\theta_{P}}\left(i_{L r P}-i_{L m 1 P}\right) \mathrm{d} \theta+\int_{0}^{\theta_{P_{0}}}\left(i_{L r P_{0}}-i_{L m 1 P_{0}}\right) \mathrm{d} \theta\right. \\
& \left.+\int_{0}^{\theta_{N_{0}}}\left(i_{L m 1 N_{0}}-i_{L r N_{0}}\right) \mathrm{d} \theta\right] .
\end{aligned}
$$

It can be seen from the running state of the converter that mode $\mathrm{O}$ exists before and after mode $\mathrm{P}$, and we get 


$$
u_{n V_{O} O}\left(\theta_{O}\right)=1 .
$$

Mode $\mathrm{O}_{0}$ is connected to mode $\mathrm{N}_{0}$, and at the end of mode $\mathrm{O}_{0}$, we get

$$
u_{n V_{O} O_{0}}\left(\theta_{\mathrm{O} 0}\right)=-1 .
$$

When the input voltage is $V_{\text {in }}=V_{A B}$, the phase-shifting angle $\theta$ of mode $\mathrm{P}$ and mode $\mathrm{O}$ is the same as the operating angle of the input voltage. It yields

$$
\theta_{P}+\theta_{O}=\theta .
$$

The operating angle of each stage in the first half of the cycle is the sum of the operating angles of each stage. It yields

$$
\theta_{H}=\pi \text {. }
$$

Given power $P$ and phase-shifting angle $\theta$, each mode equation system can be solved according to the above conditions. For the $\mathrm{P}$ and OPO states, the phase-shifting angle at this time is $\pi$, and the frequency is the resonant frequency. Therefore, the above equations can be used to describe the operating state of L-LLC-BDC accurately during the soft startup.

According to the equations and constraints of the six operating states of the converter, the voltage gain characteristics of the converter can be obtained, as shown in Figure 7. At a fixed transmission power, when the phaseshifting angle $\theta$ increases from 0 to $\pi$, the voltage gain $M$ of the converter will also increase monotonously.

Since there is a one-to-one correspondence between phase-shifting angle $\theta$ and the voltage gain $M$, the limiting current is obtained by a numerical algorithm during soft startup, as shown in Figure 8. $V_{s}$ is the steady-state output voltage. An analysis of Figure 6 shows that the current value of the P mode is always the largest in each operating state of the converter. Therefore, it is only necessary to calculate the peak resonance current $i_{p}$ of mode $\mathrm{P}$ corresponding to the output voltage $V_{0}$ and the phase-shifting angle $\theta$ in the six operating states. A series of data of the phase-shifting angle $\theta$ corresponding to the output voltage $V_{o}$ are solidified in the DSP, with 1024 points collected. An appropriate phaseshifting angle $\theta$ can be found according to the output voltage $V_{o}$ by looking up the table during the soft startup. In actual engineering, a reasonable limiting current value $i_{\text {lim }}$ can be designed. Figure 9 indicates the relationship between output voltage and phase-shifting angle when the limit current is $17 \mathrm{~A}$.

In order to analyze the dynamic process between hard start and soft start, the current variation curves of the converter in hard startup and soft startup are obtained by simulation, as shown in Figure 10. At 0.1 s, it can be seen that the current at the primary side of the converter increases instantaneously during the hard startup. The primary side current has reached about $25 \mathrm{~A}$ at $0.2 \mathrm{~s}$ when the phase- shifting soft startup starts at $0.1 \mathrm{~s}$. Therefore, both hard startup and phase-shifting soft startup are not the best choice for converter. In this paper, limiting current is added on the basis of phase-shifting soft startup. The limiting current is 1.1 times of the maximum peak current, and it is up to $17 \mathrm{~A}$ at $0.2 \mathrm{~s}$. This control strategy enables the converter to establish the output voltage quickly and smoothly on the basis of small starting current.

\section{Experimental Verification}

In order to verify the soft start-up control strategy proposed in this paper, the experimental device of L-LLC resonant bidirectional DC-DC converter is designed, as shown in Figure 11.

The output voltage $V_{o}$ is $380 \mathrm{~V}$, the device varies from $630 \mathrm{~V}$ to $890 \mathrm{~V}$ in input voltage, the rated input voltage of the device $V_{\text {in }}$ is $760 \mathrm{~V}$, and the resonance frequency $f_{s}$ is $100 \mathrm{kHz}$. The operating frequency range is $80-120 \mathrm{kHz}$. The model parameters for the L-LLC-BDC converter are shown in Table 1. The comparison between hard start, phaseshifting soft start, and phase-shifting soft start control strategy based on limiting current is shown in Figures 12-16.

Due to the presence of the transient process of hard start in experiment, the input voltage is set to $200 \mathrm{~V}$. We can see that the current spike of the converter under no-load has reached nearly $55 \mathrm{~A}$ as shown in Figure 12 . The higher the voltage, the greater the current inrush.

The peak value of the resonance current at the resonance operating point is

$$
i_{P}=\frac{V_{O}}{4 n R_{L}} \sqrt{\frac{n^{4} R_{L}^{2} T^{2}}{L_{m 1}^{2}}+4 \pi^{2}}+\frac{\sqrt{2} \operatorname{Tn} V_{O}}{4 \sqrt{3} L_{m 2}}=15.2(A) .
$$

The peak value of the resonance current under full-load conditions is calculated by each operating state. The peak value of the resonance current is obtained by equation (13), which is $15.2 \mathrm{~A}$. Resonant current is limited according to 1.1 times of peak current, and the value of resonant current is $17 \mathrm{~A}$. Figures 13 and 14 show the comparison between phase-shifting soft start and phase-shifting soft start control strategy based on limiting current under full load conditions when the input voltage is $760 \mathrm{~V}$. The current of the primary side $i_{\mathrm{p}}$ is limited to $17 \mathrm{~A}$ in Figure 13, and it is up to $25 \mathrm{~A}$ in Figure 14. The starting current is reduced significantly by the phase-shifted soft-start based on limiting current control strategy, and the time of setting up the output voltage $V_{\mathrm{O}}$ is within $12 \mathrm{~ms}$. Figures 15 and 16 are the waveforms of the current $i_{\mathrm{p}}$ and output voltage $V_{\mathrm{O}}$ under no-load condition. Similarly, the resonant current is effectively suppressed, and the startup time is shorter in Figure 15. However, the problem of output voltage floating high will appear during no-load soft startup, it can be solved by burst-mode control. 


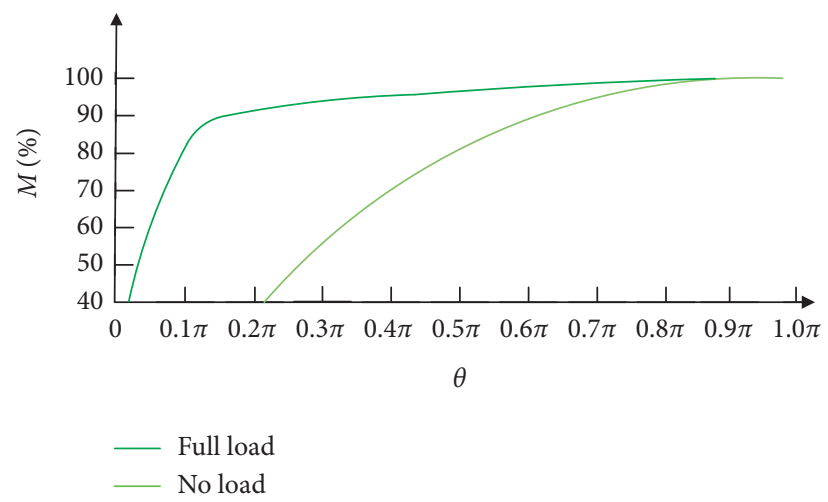

Figure 7: Voltage gain characteristics of L-LLC-BDC.

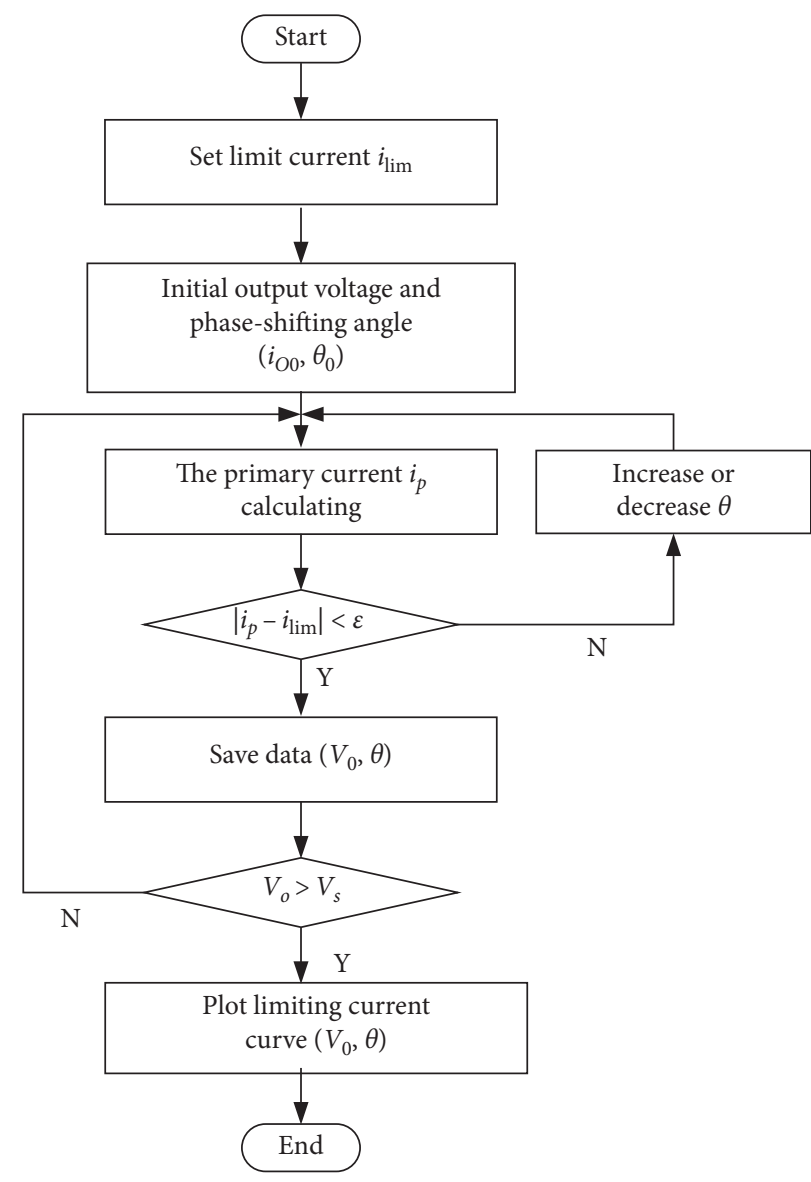

FIgURE 8: Numerical algorithm for the current-limiting curve of L-LLC-BDC. 


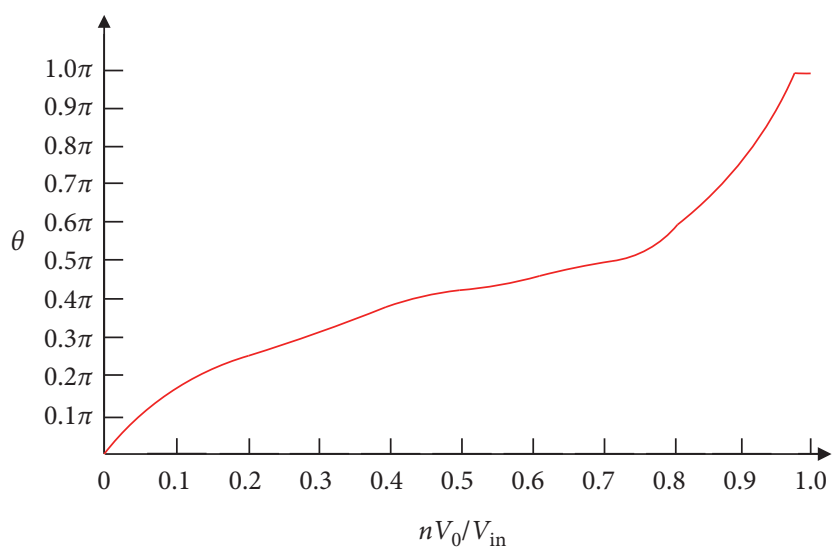

Figure 9: Current limit curve during soft startup.

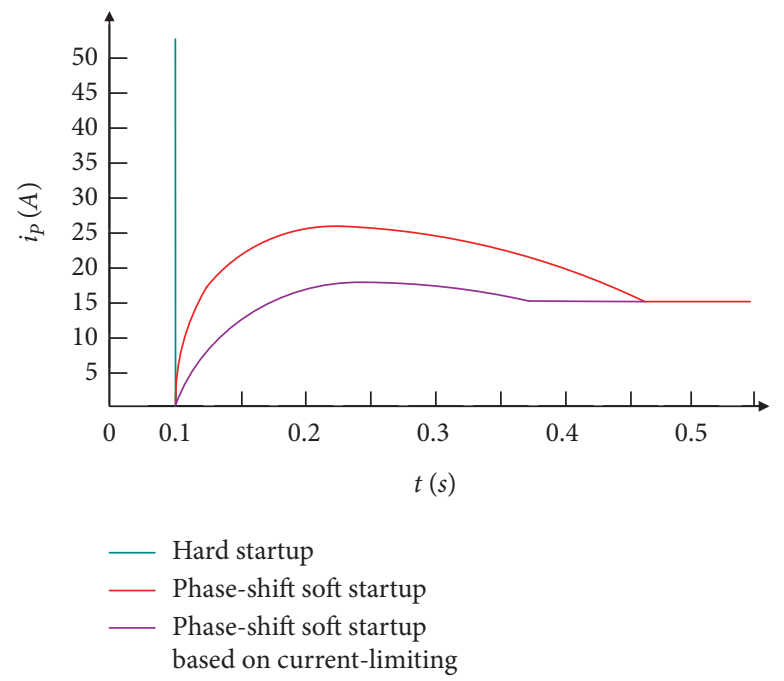

FIgURE 10: The current curve of $I_{p}$ under three conditions.

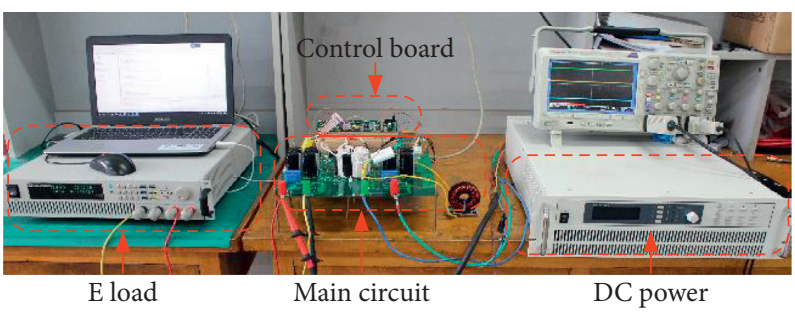

Figure 11: Physical photo of test circuit topology.

TABLE 1: The model parameters of the converter.

\begin{tabular}{lcc}
\hline Symbol & Quantity & Parameter \\
\hline$S$ & SiC MOSFET & C2M0080120D \\
$V_{\text {in }}$ & Primary side rated voltage & $760 \mathrm{~V}$ \\
$V_{o}$ & BDC secondary side rated voltage & $380 \mathrm{~V}$ \\
$P$ & BDC rated power & $6 \mathrm{~kW}$ \\
$L_{m 1}$ & BDC magnetic inductance & $0.614 \mathrm{mH}$ \\
$\mathrm{n}$ & BDC transformer ratio & $2: 1$ \\
$L_{r}$ & BDC resonant inductance & $0.087 \mathrm{mH}$ \\
$C_{r}$ & BDC resonant capacitance & $29.1 \mathrm{nF}$ \\
$L_{m 2}$ & BDC additional inductance & $0.614 \mathrm{mH}$ \\
$f$ & Resonant frequency & $100 \mathrm{kHz}$ \\
\hline
\end{tabular}




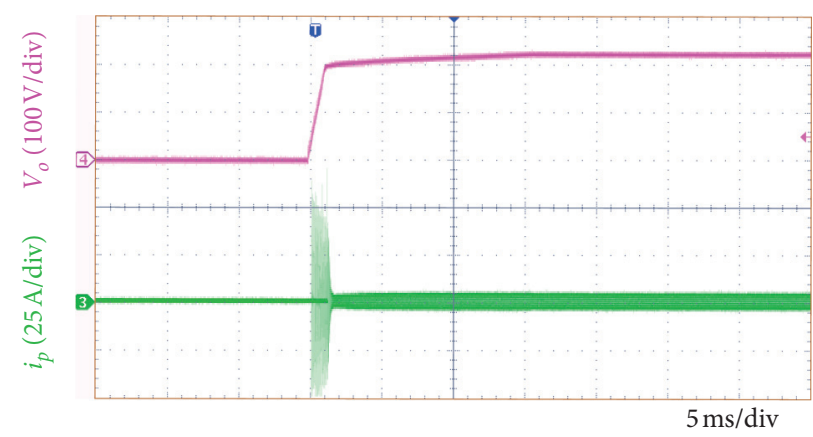

Figure 12: Waveforms of hard startup.

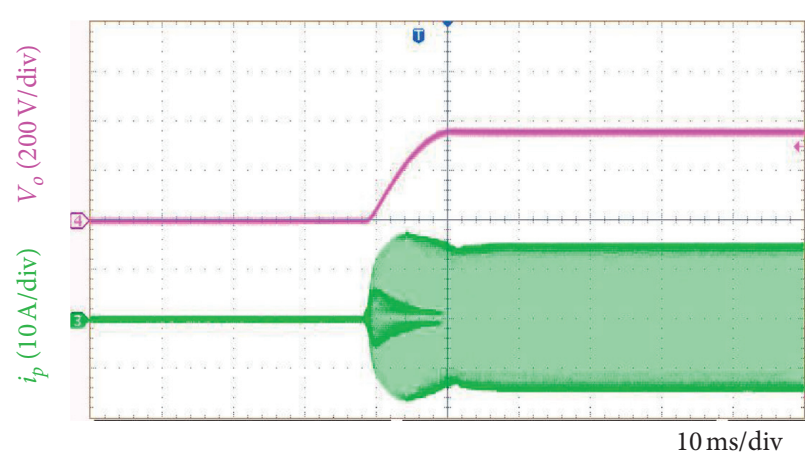

(a)

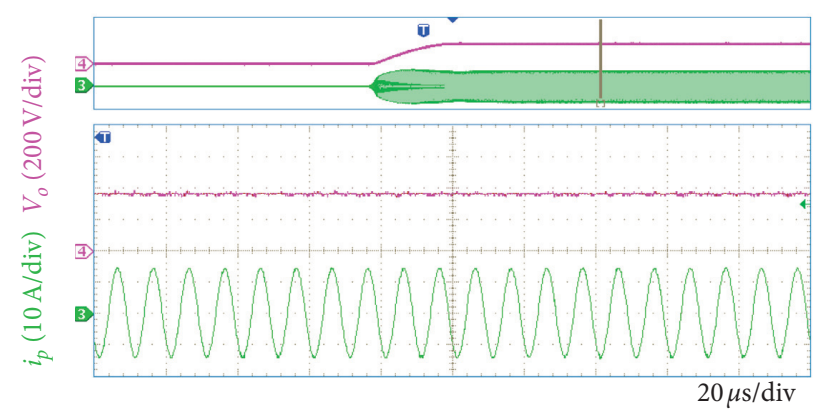

(b)

FIGURE 13: The experiment waveforms of phase-shift soft startup based on current-limiting under full load. (a) The waveforms of output voltage and primary current. (b) The detail waveforms of output voltage and primary current.

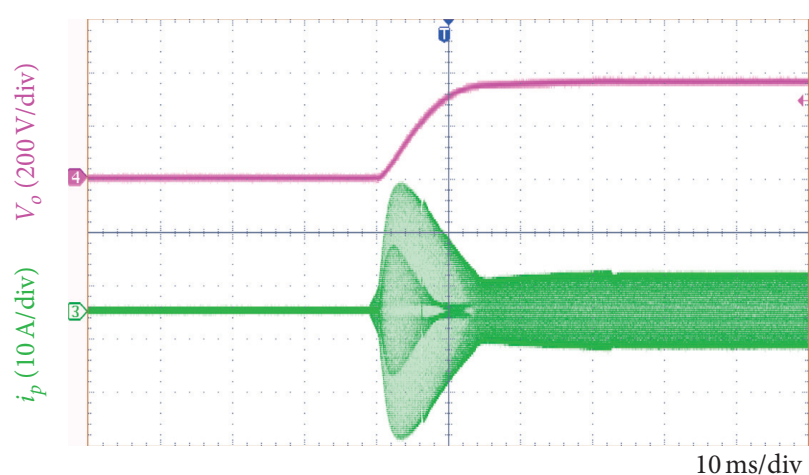

(a)

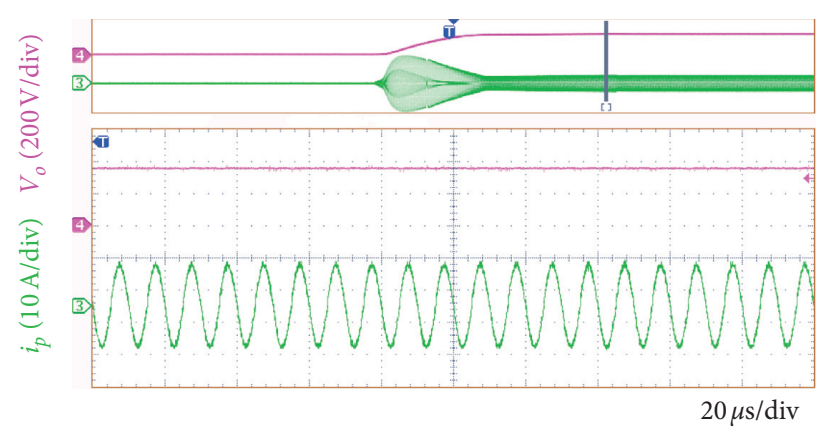

(b)

FIGURE 14: The experiment waveforms of phase-shift soft startup under full load. (a) The waveforms of output voltage and primary current. (b) The detail waveforms of output voltage and primary current. 


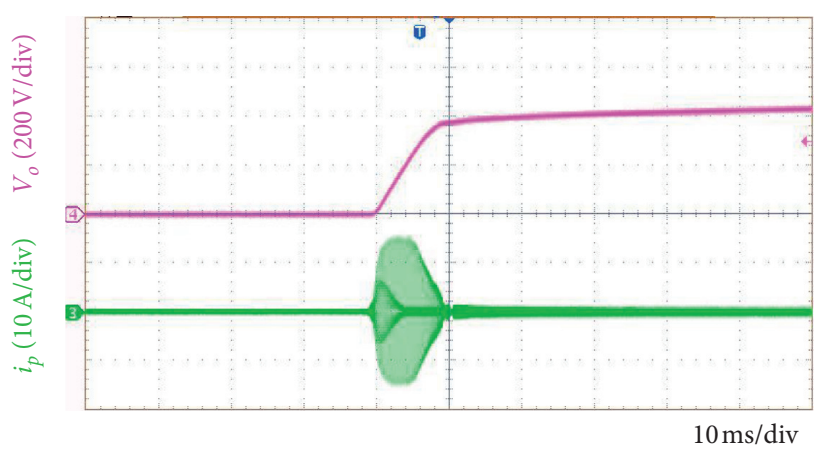

(a)

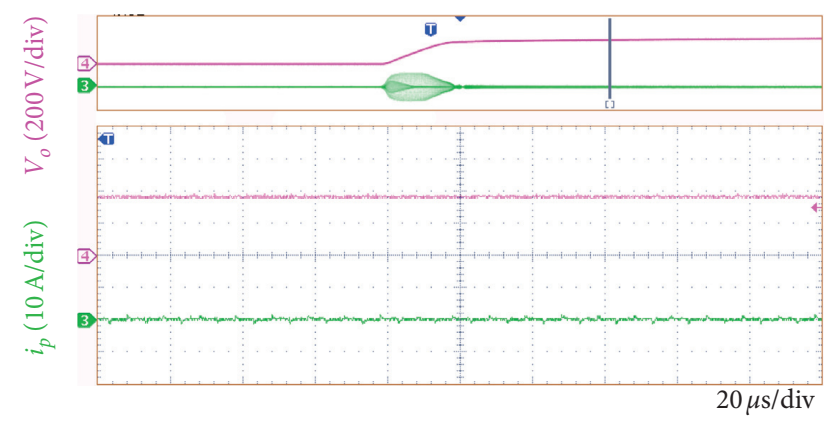

(b)

FIGURE 15: The experiment waveforms of phase-shift soft startup based on current-limiting under no load. (a) The waveforms of output voltage and primary current. (b) The detail waveforms of output voltage and primary current.

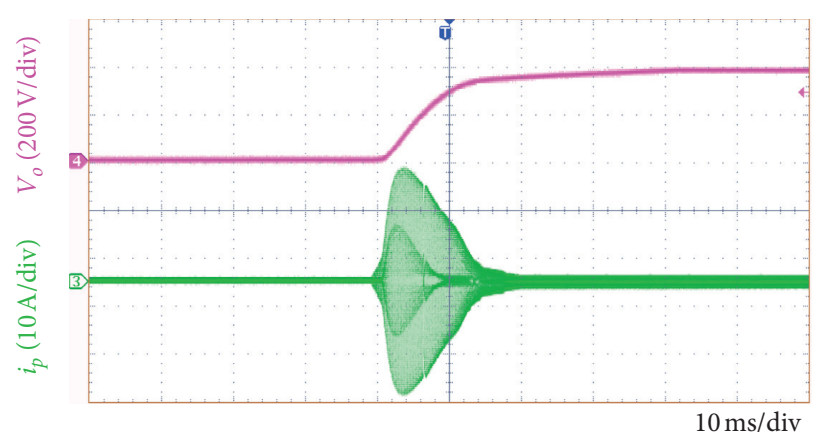

(a)

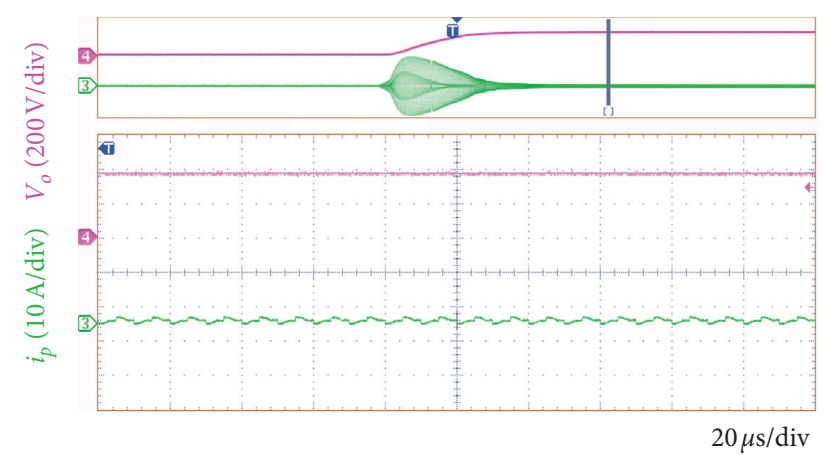

(b)

FIGURE 16: The experiment waveforms of phase-shift soft startup under no load. (a) The waveforms of output voltage and primary current. (b) The detail waveforms of output voltage and primary current.

\section{Conclusion}

L-LLC-BDC will generate a large resonance current and voltage surge during the startup process, posing a threat to the safe operation of power devices. Although a very high starting frequency can effectively suppress the impact, it will also increase the output current demand of the ICs. This paper presents a phase-shifting soft-start control strategy based on the current-limiting curve. At the resonant frequency point, the peak value of the startup current is obtained according to numerical algorithm during the startup process. Through this current curve, a one-to-one correspondence between the output voltage and the phase shift angle of the switch is obtained. Experiments show that the control strategy can effectively suppress the resonant current, and the startup time is also shorter at the resonant frequency point.

\section{Data Availability}

The data used to support the findings of this study are available from the corresponding author upon request.

\section{Conflicts of Interest}

The authors declare that they have no conflicts of interest.

\section{Acknowledgments}

This work was supported by the National Natural Science Foundation of China under grant no. 51677151.

\section{References}

[1] B. Lu, W. Liu, Y. Liang, F. C. Lee, and J. D. Van Wyk, "Optimal design methodology for LLC resonant converter," in Proceedinds of the IEEE Applied Power Electronics Conference and Exposition, pp. 1-6, Hanoi, Vietnam, March 2006.

[2] X. Fang, H. Hu, F. Chen et al., "Efficiency-oriented optimal design of the LLC resonant converter based on peak gain placement," IEEE Transactions on Power Electronics, vol. 28, no. 5, pp. 2285-2296, 2013.

[3] R. Yu, G. K. Y. Ho, B. M. H. Pong, B. W.-K. Ling, and J. Lam, "Computer-aided design and optimization of high-efficiency LLC series resonant converter," IEEE Transactions on Power Electronics, vol. 27, no. 7, pp. 3243-3256, 2012.

[4] A. Mustafa and S. Mekhilef, "Dual phase LLC resonant converter with variable frequency zero circulating current phase-shift modulation for wide input voltage range applications," IEEE Transactions on Power Electronics, vol. 36, no. 3, pp. 2793-2807, 2020.

[5] Z. Li, B. Xue, and H. Wang, "An interleaved secondary-side modulated LLC resonant converter for wide output range applications," IEEE Transactions on Industrial Electronics, vol. 67, no. 2, pp. 1124-1135, 2020. 
[6] J.-H. Jung, H.-S. Kim, M.-H. Ryu, and J.-W. Baek, "Design methodology of bidirectional CLLC resonant converter for high-frequency isolation of DC distribution systems," IEEE Transactions on Power Electronics, vol. 28, no. 4, pp. 17411755, 2013.

[7] T. Jiang, J. Zhang, X. Wu, K. Sheng, and Y. Wang, "A bidirectional LLC resonant converter with automatic forward and backward mode transition," IEEE Transactions on Power Electronics, vol. 30, no. 2, pp. 757-770, 2015.

[8] P. Electronics, "Soft start scheme for resonant converters having variable frequency control," U.S. Patent US6 154 375(A), 1999.

[9] W. Feng and C. L. Lee, "Optimal trajectory control of LLC resonant converter for soft start-up," IEEE Trans. Power Electron.vol. 29, no. 3, pp. 1461-1468, 2014.

[10] Y. Wei, Q. Luo, and A. Mantooth, "Overview of modulation strategies for LLC resonant converter," IEEE Transactions on Power Electronics, vol. 35, no. 10, pp. 10423-10443, 2020.

[11] L. Shi, B. Liu, and S. Duan, "Burst-mode and phase-shift hybrid control method of LLC converters for wide output range applications," IEEE Transactions on Industrial Electronics, vol. 67, no. 2, pp. 1013-1023, 2020.

[12] H.-P. Park, M. Kim, and J.-H. Jung, "Investigation of zero voltage switching capability for bidirectional series resonant converter using phase-shift modulation," IEEE Transactions on Power Electronics, vol. 34, no. 9, pp. 8842-8858, Sept. 2019.

[13] B. Xue, H. Wang, J. Liang, Q. Cao, and Z. Li, "Phase-shift modulated interleaved LLC converter with ultrawide output voltage range," IEEE Transactions on Power Electronics, vol. 36, no. 1, pp. 493-503, 2021.

[14] D. Yang, C. Chen, S. Duan, J. Cai, and L. Xiao, "A Variable duty cycle soft startup strategy for LLC series resonant converter based on optimal current-limiting curve," IEEE Transactions on Power Electronics, vol. 31, no. 11, pp. 79968006, 2016.

[15] W. Guo, K. Bai, A. Taylor, J. Patterson, and J. Kane, "A novel soft starting strategy of an LLC resonant DC/DC converter for plug-in hybrid electric vehicles," in Proceedings of the 28th Annual IEEE Applied Power Electronics Conference and Exposition, APEC 2013, pp. 2012-2015, Long Beach, LA, USA, March 2013.

[16] M. Kumar, L. Huber, and M. M. Jovanovic, "Startup procedure for DSP-controlled Three-phase six-switch boost PFC rectifier," IEEE Transactions on Power Electronics, vol. 30, no. 8, pp. 4514-4523, 2015.

[17] C. Fei, F. C. Lee, and Q. Li, "Digital implementation of soft start-up and short-circuit protection for high-frequency LLC converters with optimal trajectory control (OTC)," IEEE Transactions on Power Electronics, vol. 32, no. 10, pp. 80088017, 2017.

[18] R. Zheng, B. Liu, and S. Duan, "Analysis and parameter optimization of start-up process for LLC resonant converter," IEEE Transactions on Power Electronics, vol. 30, no. 12, pp. 7113-7122, 2015.

[19] N. Hou and W. Song, "Full-bridge isolated DC/DC converters with triple-phase-shift control and soft starting control method," Proceedings of the CSEE, vol. 35, no. 23, pp. 61136121, 2015.

[20] Q. Chen, J. Wang, and Y. Ji, "Control scheme of bi-directional LLC resonant DC-DC transformer for soft start and power conversion," Transactions of China Electrotechnical Society, vol. 29, no. 08, pp. 180-186, 2014.

[21] L. Zhang, J. Qin, X. Wu, S. Debnath, and M. Saeedifard, "A generalized precharging strategy for soft startup process of the modular multilevel converter-based HVDC systems," IEEE Transactions on Industry Applications, vol. 53, no. 6, pp. 5645-5657, 2017.

[22] S. Du, B. Wu, and N. R. Zargari, "A startup method for flyingcapacitor modular multilevel converter (FC-MMC) with effective damping of LC oscillations," IEEE Transactions on Power Electronics, vol. 32, no. 7, pp. 5827-5834, 2017.

[23] D. He, W. Cai, F. Yi et al., "Control Algorithm for soft start of split-AC-switched-reluctance motor drives," IEEE Transactions on Industry Applications, vol. 53, no. 6, pp. 5479-5488, 2017.

[24] Y. Tang, S. Xie, C. Zhang, and Z. Xu, "Improved Z-source inverter with reduced Z-source capacitor voltage stress and soft-start capability," IEEE Trans. Power Electron.vol. 24, no. 2, pp. 409-415, 2009.

[25] L. Huang, P. Luo, C. Wang, and X. Zhou, "A high speed onchip soft-start technique with high start-up stability for current-mode DC-DC converter," IEEE Access, vol. 2019, no. 7, pp. 27579-27585, 2019.

[26] S. Pugliese, G. Buticchi, R. A. Mastromauro, M. Andresen, M. Liserre, and S. Stasi, "Soft-start procedure for a three-stage smart transformer based on dual-active bridge and cascaded H-bridge converters," IEEE Transactions on Power Electronics, vol. 35, no. 10, pp. 11039-11052, 2020.

[27] Z. Lv, X. Yan, and L. Sun, "A L-LLC resonant bidirectional DC-DC converter based on hybrid control of variable frequency and phase shift," Transactions of China Electrotechnical Society, vol. 32, no. 4, pp. 12-24, 2017.

[28] X. Sun, Y. Shen, W. Li, and H. Wu, "A PWM and PFM hybrid modulated three-port converter for a standalone PV/Battery power system," IEEE Journal of Emerging and Selected Topics in Power Electronics, vol. 3, no. 4, pp. 984-1000, 2015.

[29] X. Fang, H. Hu, Z. J. Shen, and I. Batarseh, "Operation mode analysis and peak gain approximation of the LLC resonant converter," IEEE Transactions on Power Electronics, vol. 27, no. 4, pp. 1985-1995, 2012.

[30] H. HU, W. Wang, W. Sun, S. Ding, and Y. Xing, "Optimal efficiency design of LLC resonant converter," Proceedings of the CSEE, vol. 33, no. 18, pp. 48-56, 2013. 